\title{
PALEOECOLOGY AND TAPHONOMY OF A PLIOCENE CORAL THICKET FROM THE YORKTOWN FORMATION OF VIRGINIA
}

BAILEY*, Richard, H., Department of Geology, Northeastern University, Boston, MA 02115, U.S.A.; BLOW, Warren, C., Department of Paleobiology E-501, National Museum of Natural History, Washington, DC 20560, U.S.A.

A Septastrea sp. coral thicket ( 0.2 to $0.5 \mathrm{~m}$ thick), exposed for about $280 \mathrm{~m}$ along the north bank of the Piankatank River in southeastern Virginia, occurs with a diverse shallow to mid-shelf molluscan assemblage dominated by Chesapecten, Marvacrassatella, Spisula, Dosinia, Mercenaria, Astarte, Cyclocardia, Glycymeris, Ostrea, Ecphora, and Turritella. The thicket is contained within silty, fine to medium sands of the uppermost portion of the Sunken Meadow Member $(0.7 \mathrm{~m}$ exposed) of the late Pliocene Yorktown Formation. Quartzose cross-bedded coquina (1.3 m exposed) of the Rushmere Member of the Yorktown directly overlies the coral thicket. The coquina strata contains abundant Ophiomorpha, and other large coquina-filled burrows which cross the basal Rushmere unconformity and extend into underlying thicket strata. Within the thicket many of these coquina-filled burrows and galleries occur beneath the shelter of Septastrea branches and coralla. The predominant coral fabric is a laterally extensive but discontinuous irregular coppice (20 to $40 \mathrm{~cm}$ thick) of horizontal and tangled cylindrical branches and ramose to palmate branch fragments. Intercalated within these biostromal layers are large bases or trunks of coralla (up to $30 \mathrm{~cm}$ high) lacking uppermost branches and very large (up to $0.4 \mathrm{~m} \mathrm{long}$ ) fragments of thick palmate branches. One very large corallum ( $40 \mathrm{~cm}$ wide and 50 $\mathrm{cm}$ high) was a massive irregular or boulder-like head in approximate upright growth position.

Thicket growth began with larval settlement on shell substrata. Coralla in this early stage were small columnar to ramose forms which grew to heights of approximately 20 to $30 \mathrm{~cm}$ and branch thicknesses of 1 to $3 \mathrm{~cm}$ before being toppled and/or broken. Counts of annual growth increments of broken cylindrical branch fragments ( 3.0 to $3.5 \mathrm{~cm}$ in diameter) from coralla at this stage indicate approximate minimum ages of 10 to 15 years. A much smaller number of coralla rotated into stabilized positions in the substratum after which they greatly increased the size and mass of the basal portion of the head by fusing areas between lower portions of branches. These fused cylindrical branches were further enlarged by concentric growth into stout palmate branches supported by a massive corallum base. A few coralla developed into massive, irregular boulder-like heads by fusing palmate branches and attaining a gravitationally stabilized position. The top and bottom of the largest head projected above and below a coppice of surrounding branch fragments. Extrapolation of growth rates from smaller specimens suggests that these large massive heads may be 100 to 200 years old. Although the growth and development of the thicket may have proceeded through successional stages, there is no evidence preserved in thicket fabric for discrete stages. Similarly, there is little evidence for autogenic successional changes in associated molluscan assemblages. Subtle changes in the composition and fabric of molluscan assemblages below, within, and above the thicket suggest allogenic control (possibly a slight increase in water depth and lower energy) independent of thicket development.

Exposed solid substrata provided by coralla and branches were extensively bored by lithophagid bivalves, clionid sponges, and polychaetes. Epibionts, particularly Balanus and Ostrea, grew on both living and dead coral. In one instance, barnacles were overgrown by continued growth of a corallum. A combination of pre-burial abrasion and post-burial diagenesis destroyed all morphological details of corallites. The thicket community developed in a moderate energy, shallow to mid-shelf environment with depths generally below fair weather wave base. In such a setting normal wave and shelf currents prevented rapid burial of the living thicket and allowed borers and epibionts to utilized coral substrata. Periodic storms lowered wave base and generated currents capable of disrupting and toppling most coralla. Larger coralla were able to survive major storms. The thicket assemblage thus represents a dynamic but long-term paleocommunity. 